\title{
Pharmacokinetics of Nafcillin in Patients with Renal Failure
}

\author{
CARLOS R. DIAZ, JAMES G. KANE,* RICHARD H. PARKER, AND FRANK R. PELSOR
}

Section of Infectious Diseases, Medical Service, Veterans Administration Hospital, Washington, D.C. 20422

Received for publication 17 January 1977

Nafcillin, a pencillinase-resistant penicillin, is frequently used for treatment of staphylococcal infections in hemodialysis patients. Despite its widespread use, there is a paucity of available data regarding the pharmacokinetics of nafcillin in hemodialysis patients. Therefore, sodium nafcillin, $25 \mathrm{mg} / \mathrm{kg}$, was given intravenously over a 5 - to 15 -min period to 12 hemodialysis patients. Eleven patients were studied during dialysis, and eight of these were studied again during the interdialysis period. The initial serum half-life for nafcillin was 0.208 $\mathrm{h}$ during dialyses and $0.278 \mathrm{~h}$ between dialyses. The terminal half-life was $1.48 \mathrm{~h}$ during dialyses and $1.89 \mathrm{~h}$ between dialyses. There was no statistically significant difference between these values. These data indicate that renal failure does not appreciably affect the serum half-life of nafcillin, and hemodialysis does not accelerate the rate of clearance of nafcillin from the blood. Therefore, no modification of the usual nafcillin dosage is necessary when using this drug in hemodialysis patients.

Sodium nafcillin, a semisynthetic penicillin derived from 6-aminopenicillanic acid, has been used extensively since its introduction in 1963. Due to its efficacy against penicillinase-producing staphylococci, nafcillin is often considered the drug of choice for treatment of infections caused by these microorganisms (5). Because a large fraction of an administered dose is cleared by hepatic excretion (4), it is often chosen from among other semisynthetic penicillins for the treatment of staphylococcal infections in patients on chronic hemodialysis. However, there are very sparse data concerning the pharmacokinetics of nafcillin in these patients. Current recommendations on dosage adjustment are based on empirical observation, and therefore the hazards always exist of neurotoxicity, if excessive blood levels are attained (2), or progression of the infection, if subtherapeutic levels are present. These hazards were emphasized in a recent study on the use of penicillin $G$ in anuric patients (1). Despite many years of empirical therapeutic regimens of penicillin $G$ in patients on hemodialysis, the study led to drastic reductions in the recommended dosage employed in this setting. Most recently, in a study by Rudnick and co-workers (9), it was found that the half-life of nafcillin after a single 500$\mathrm{mg}$ intramuscular injection in patients with renal failure was unchanged from that seen in patients with normal renal function. However, the small dose and intramuscular administration used in the above study does not reflect the usual clinical setting. This paper reports the results of a prospective study undertaken to determine the excretion curve and half-life of nafcillin in patients with renal failure on hemodialysis, using currently recommended doses (5).

\section{MATERIALS AND METHODS}

Patients were eligible for the study if: (i) they were anuric and on chronic hemodialysis; (ii) there was no history of penicillin allergy; and (iii) hepatic function was normal as determined by serum glutamic oxaloacetic transaminase, alkaline phosphatase, albumin, and bilirubin measurements. Informed consent was obtained from all patients. Skin testing for sensitivity to nafcillin was then performed. Before administration of nafcillin, a sample of blood was obtained for assay of intrinsic antimicrobial activity. The sodium nafcillin vials, each containing $1 \mathrm{~g}$ of the drug, were reconstituted with sterile water immediately before administration. A dose of $25 \mathrm{mg} / \mathrm{kg}$ was diluted to a volume of $100 \mathrm{ml}$ with $5 \%$ dextrose in water and infused over a 5- to 15-min period. During the dialysis period, the infusion was done through the functioning vascular access channel. A second blood sample for determination of the peak nafcillin level was obtained $15 \mathrm{~min}$ after cessation of the infusion, and hemodialysis was begun. Subsequent blood samples were drawn at the specified intervals shown in Fig. 1.

During the interdialysis period, the infusion was done through a 19-gauge needle inserted in a peripheral vein. This intravenous line was then removed immediately after the infusion of the drug. The study was conducted for $5 \mathrm{~h}$, blood samples being drawn as specified in Fig. 2.

All samples were collected in 7-ml siliconized Vacutainer (Becton, Dickinson \& Co., Rutherford, 


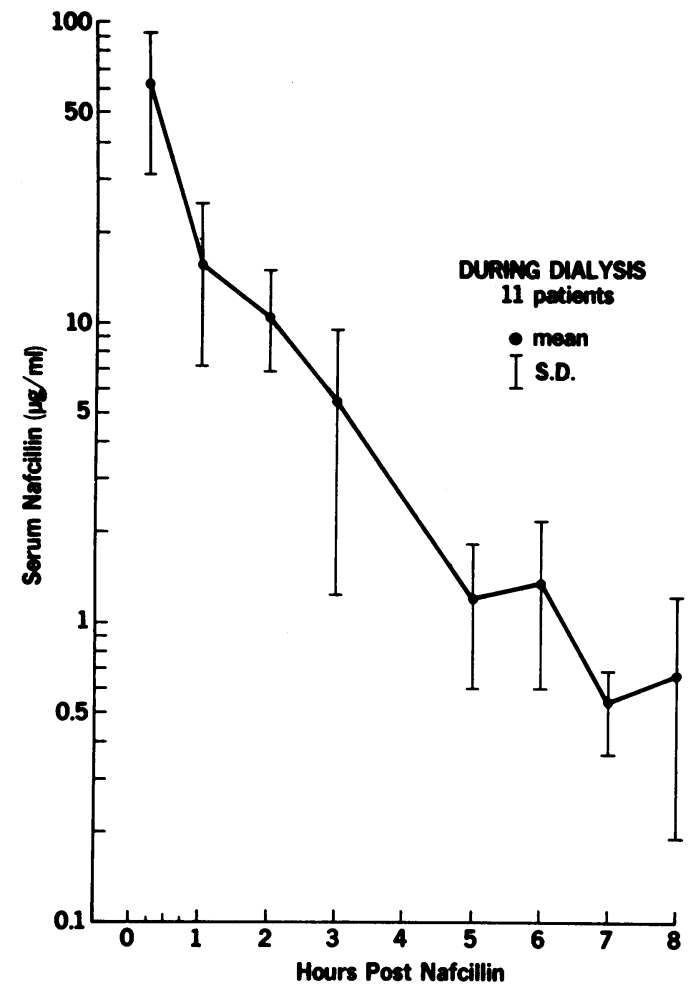

Fig. 1. Mean serum levels of nafcillin during dialysis after intravenous infusion of nafcillin, $25 \mathrm{mg} /$ $\mathrm{kg}$, over 5 to $15 \mathrm{~min}$.

N.J.) tubes and kept at room temperature for 30 min until a clot formed. The serum was separated by centrifugation and kept frozen at $-20^{\circ} \mathrm{C}$ until assayed. No gerum was kept frozen longer than 4 weeks before assay.

Antibiotic level determinations and calculations. The serum levels of nafcillin were determined by Wyeth Laboratories, Philadelphia, Pa., using the basic bioassay method of Grove and Randall (3). Sarcina lutea ATCC 9341 was used as the test organism. A nonlinear least-squares regression program was used to fit a biexponential curve to the serum decay data, and was based on the following formula (8):

$$
C_{p}=A_{1} e^{-b} t+A_{2} e^{-b} t
$$

where $C_{p}$ is the nafcillin serum concentration as a function of time and $A_{1}, A_{2}, b_{1}$, and $b_{2}$ are constants determined by the regression analysis. Initial and terminal half-lives for the biphasic serum decay curve were calculated for each constant $b$ according to the following equation (8): $t_{1}=0.693 / b$.

The mean serum nafcillin values for each specified time were then plotted on semilogarithmic scales (Fig. 1 and 2).

\section{RESULTS}

Twenty studies were performed on 12 patients. Eleven patients were studied during di- alysis, and eight of these were studied again during the interdialysis period. One patient, who was receiving nafcillin for a staphylococcal fistula infection, was studied only during the interdialysis period. Patient doses ranged from 1.6 to $2.4 \mathrm{~g}$, with a mean of $1.9 \mathrm{~g}$ of nafcillin per dose.

Interdialysis. Table 1 shows the serum nafcillin levels obtained at the time intervals studied. There was a wide variation in levels, ranging from a high of 332.1 to $33.2 \mu \mathrm{g} / \mathrm{ml}$ at $15 \mathrm{~min}$ postinfusion to a nadir of 2.4 to $0.6 \mu \mathrm{g} / \mathrm{ml}$ at $5 \mathrm{~h}$ postinfusion, with a mean of 145 and $1.2 \mu \mathrm{g} / \mathrm{ml}$, respectively. Figure 2 illustrates the curve defined by the mean serum levels plotted against time. The computed individual initial serum half-life of nafcillin during the interdialysis period was $0.278 \mathrm{~h}$; the mean terminal half-life was $1.89 \mathrm{~h}$.

Hemodialysis. Table 2 gives the results of serum nafcillin level determinations during dialysis. The variations in serum nafcillin levels among individuals were less marked than those seen in the interdialysis period. The nafcillin concentration ranged from a peak of 113.4 to $19.5 \mu \mathrm{g} / \mathrm{ml}$ at $15 \mathrm{~min}$ to a nadir of 1.32 to 0.064 $\mu \mathrm{g} / \mathrm{ml}$ at $8 \mathrm{~h}$, with mean values of 63.4 and 0.68 $\mu \mathrm{g} / \mathrm{ml}$, respectively. Figure 1 depicts the mean curve of the serum levels against time. The

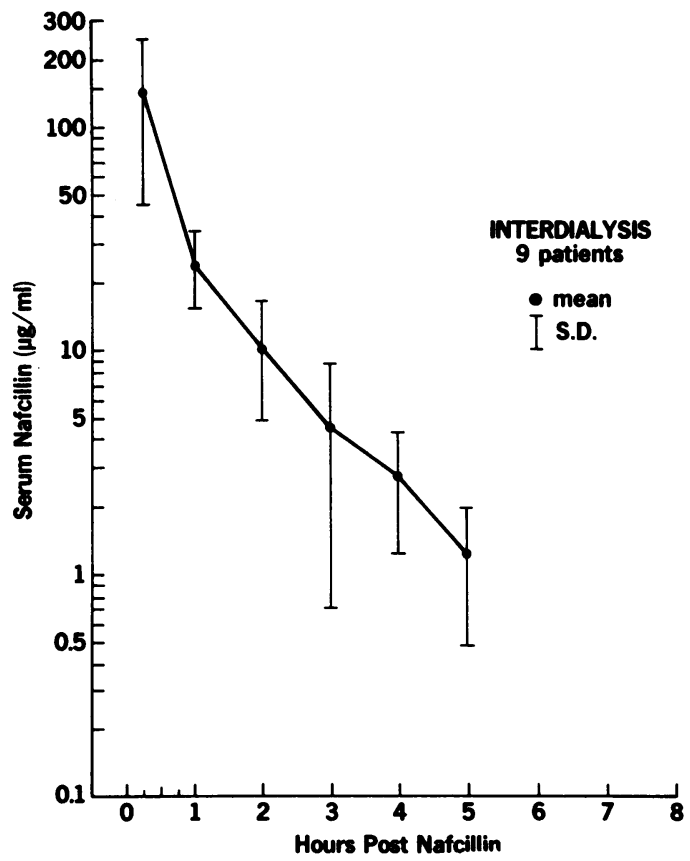

Fig. 2. Mean serum levels of nafcillin during the interdialysis period after intravenous infusion of nafcillin, $25 \mathrm{mg} / \mathrm{kg}$, over 5 to $15 \mathrm{~min}$. 
initial mean half-life (Table 3) of nafcillin during hemodialysis was $0.208 \mathrm{~h}$; the mean terminal half-life was $1.48 \mathrm{~h}$. Tests of statistical significance using the modified $t$ test revealed no difference between the initial and terminal serum half-lives of nafcillin during hemodialysis compared with the interdialysis period, respectively.

\section{DISCUSSION}

Dose determination of antimicrobial agents given patients with chronic renal failure is often difficult because of the altered excretion rates of various drugs in renal failure. Previous studies have reported that the half-life of nafcillin in normal patients after 0.5 -g doses given intramuscularly is in the range of 0.5 to $1 \mathrm{~h}$ (10). The peak serum level at that dosage may range widely: 1.5 to $50 \mu \mathrm{g} / \mathrm{ml}$ (9). Although as much as $30 \%$ of an administered dose may be excreted in the urine, the greatest portion is excreted in bile and enters the enterohepatic circulation $(4,7)$. The degree of hepatic excre- tion, combined with a high therapeutic index, may account for the paucity of adequate studies regarding the pharmacokinetics of this drug in anuric patients.

The present study was designed to approximate the usual clinical situation. Hence, the drug was administered as an intravenous bolus, in a dosage usually employed for treatment of life-threatening staphylococcal infections. The use of a single-pass system of hemodialysis precluded the computation of drug dialysance, and the biological half-life was used as the measure of drug excretion. The data revealed that the half-life of nafcillin in patients with renal failure after a single intravenous injection is not appreciably changed as compared with values in patients with normal renal function (9). In addition, the excretion rate and half-life were not influenced by hemodialysis.

The wide variability in the serum level of nafcillin at any given time among individual patients could not be completely explained. The

TABLE 1. Interdialysis serum nafcillin concentrations at selected time intervals after intravenous infusion of a single injection of $25 \mathrm{mg} / \mathrm{kg}$

\begin{tabular}{|c|c|c|c|c|c|c|}
\hline \multirow{2}{*}{ Patient no. } & \multicolumn{6}{|c|}{ Nafeillin concn $(\mu g / m l)$ at time $(h):$} \\
\hline & 0.25 & 1 & 2 & 3 & 4 & 5 \\
\hline $\begin{array}{l}1 \\
2 \\
3 \\
4 \\
5 \\
6 \\
7 \\
8\end{array}$ & $\begin{array}{r}33.21 \\
201.69 \\
131.22 \\
195.00 \\
56.48 \\
47.70 \\
332.10 \\
170.10\end{array}$ & $\begin{array}{r}8.91 \\
17.28 \\
29.16 \\
28.35 \\
35.10 \\
18.90 \\
37.80 \\
19.80\end{array}$ & $\begin{array}{r}2.70 \\
4.59 \\
6.30 \\
8.70 \\
26.10 \\
5.60 \\
21.60 \\
9.90\end{array}$ & $\begin{array}{r}1.32 \\
1.83 \\
3.15 \\
6.62 \\
\\
11.88 \\
3.42\end{array}$ & $\begin{array}{l}3.87 \\
1.63\end{array}$ & $\begin{array}{l}0.60 \\
0.72 \\
1.05 \\
2.43\end{array}$ \\
\hline $\begin{array}{l}\text { Mean } \pm \text { standard } \\
\text { deviation }\end{array}$ & $145 \pm 100.95$ & $24.41 \pm 9.82$ & $10.69 \pm 8.51$ & $4.70 \pm 3.97$ & $2.75 \pm 1.78$ & $1.21 \pm 0.73$ \\
\hline
\end{tabular}

TABLE 2. Serum nafcillin concentrations during dialysis at selected time intervals after intravenous infusion of a single injection of $25 \mathrm{mg} / \mathrm{kg}$

\begin{tabular}{|c|c|c|c|c|c|c|c|c|}
\hline \multirow{2}{*}{ Patient no. } & \multicolumn{8}{|c|}{ Nafcillin concn $(\mu \mathrm{g} / \mathrm{ml})$ at time $(\mathrm{h})$ : } \\
\hline & 0.25 & 1 & 2 & 3 & 5 & 6 & 7 & 8 \\
\hline $\begin{array}{l}1 \\
2 \\
3 \\
4 \\
\\
5 \\
6 \\
7 \\
8\end{array}$ & $\begin{array}{c}24.062 \\
19.500 \\
76.250 \\
68.040 \\
63.000 \\
72.90 \\
68.85 \\
75.60 \\
113.40 \\
90.00 \\
25.785\end{array}$ & $\begin{array}{l}6.50 \\
4.125 \\
8.50 \\
29.16 \\
19.20 \\
22.05 \\
11.4 \\
27.90 \\
12.60 \\
23.25 \\
8.438\end{array}$ & $\begin{array}{c}7.425 \\
13.00\end{array}$ & $\begin{array}{l}1.325 \\
\\
9.45 \\
8.91 \\
5.535 \\
2.61 \\
8.91 \\
4.05 \\
\\
2.50\end{array}$ & $\begin{array}{l}0.945 \\
1.05 \\
2.05 \\
0.75\end{array}$ & $\begin{array}{l}0.26 \\
1.425 \\
2.070 \\
1.960 \\
0.64 \\
\\
1.98\end{array}$ & $\begin{array}{l}0.57 \\
\\
0.52 \\
0.74 \\
0.34\end{array}$ & $\begin{array}{l}0.064 \\
0.115 \\
0.68 \\
0.90 \\
1.32 \\
0.42 \\
\\
1.29\end{array}$ \\
\hline Mean \pm standard deviation & $\begin{array}{r}63.40 \\
+29.24\end{array}$ & $\begin{array}{r}15.74 \\
\pm 8.89\end{array}$ & $\begin{array}{r}10.21 \\
\pm 3.94\end{array}$ & $\begin{array}{r}5.41 \\
\pm 3.29\end{array}$ & $\begin{array}{r}1.20 \\
\pm 0.58\end{array}$ & $\begin{array}{r}1.39 \\
\pm 0.77\end{array}$ & $\begin{array}{r}0.54 \\
\pm 0.16\end{array}$ & $\begin{array}{r}0.68 \\
\pm 0.52\end{array}$ \\
\hline
\end{tabular}


TABLE 3. Initial and terminal half-life values of nafcillin during hemodialysis

\begin{tabular}{ccccc}
\hline \multirow{2}{*}{ Patient no. } & \multicolumn{2}{c}{ Initial half-life $^{\infty}$} & \multicolumn{2}{c}{ Terminal half-life $^{b}$} \\
\cline { 2 - 5 } & During dialysis & Interdialysis & During dialysis & Interdialysis $^{\circ}$ \\
\hline 1 & 0.237 & 0.345 & 1.16 & 1.92 \\
2 & & 0.185 & 1.24 \\
4 & 0.345 & & 1.44 & 1.39 \\
5 & 0.080 & 0.291 & 1.92 & 1.65 \\
6 & 0.267 & 0.206 & 1.44 & \\
7 & 0.129 & & 1.19 & 4.08 \\
8 & 0.166 & & 1.73 & 1.08 \\
9 & 0.145 & & 1.03 & 1.89 \\
10 & 0.230 & 0.485 & 1.82 & 1.24 \\
11 & 0.369 & & 1.48 & \\
\hline
\end{tabular}

${ }^{a} t=1.26, \mathrm{df}=14 ;$ not significant at 0.05 level.

${ }^{b} t=1.12, \mathrm{df}=14 ;$ not significant at 0.05 legvel.

variation did not correlate with the etiology of the renal disease, the presence of a dialysis shunt as opposed to a fistula, or the type of hemodialysis apparatus. This variation may have been due to differences in infusion time in that some of the patients, because of high shunt pressures, received a slower infusion than others. This was especially true for those studied during the dialysis period. These patients received the infusion via their functioning vascular access channels rather than by a peripheral vein.

This study demonstrates that anuric patients on chronic hemodialysis do not have an altered serum half-life of nafcillin either during hemodialysis or in the interdialysis period after a single intravenous injection of the drug. The question of whether accumulation occurs after repeated doses remains to be clarified. However, the one patient in the study who was receiving nafcillin every $6 \mathrm{~h}$ for an existing infection showed no evidence of accumulation.

It is recommended that the dose of nafcillin used to treat staphylococcal infections in patients with renal impairment be identical to the dose used to treat similar staphylococcal infections in patients with normal renal function.

\section{ACKNOWLEDGMENTS}

We wish to thank George H. Warren, Sanford B. Rosenman, Lester S. Weber, and Lawrence Gordon at Wyeth Laboratories for performing the bioassays. We are indebted to the nursing and house staffs of the hemodialysis unit for their technical assistance.
This study supported by the Medical Research Service of the Veterans Administration and a grant from Wyeth Laboratories, Philadelphia, $\mathrm{Pa}$.

\section{LITERATURE CITED}

1. Bryan, C. S., and W. J. Stone. 1975. "Comparably massive" penicillin $G$ therapy in renal failure. Ann. Intern. Med. 82:189-195.

2. Fossieck, B., and R. H. Parker. 1974. Neurotoxicity during intravenous infusion of penicillin. A review. J. Clin. Pharmacol. 14:504-512.

3. Grove, D. C., and W. A. Randall. 1955. Assay methods of antibiotics. A laboratory manual, p. 34-36. Medical Encyclopedia, Inc., New York.

4. Green, G. R., and J. E. Geraci. 1965. A note on the concentration of nafcillin in human bile. Mayo Clin. Proc. 40:700-704.

5. Hoeprich, P. D. 1972. Infective endocarditis, p. 10451060. In P. D. Hoeprich (ed.), Infectious diseases: a guide to the understanding and management of infectious processes. Harper \& Row, Hagerstown, Md.

6. Kind, A. C., T. E. Tupasi, H. C. Standiford, and W. M. M. Kirby. 1970. Mechanisms responsible for plasma levels of nafcillin lower than those of oxacillin. Arch. Intern. Med. 125:685-690.

7. Klein, J. O., and M. Finland. 1963. Nafcillin antibacterial action in vitro and absorption and excretion in normal young men. Am. J. Med. Sci. 246:10-25.

8. Riegelman, S., J. C. K. Loo, and M. Rowland. 1968. Shortcomings in pharmacokinetic analysis by conceiving the body to exhibit properties of a single compartment. J. Pharm. Sci. 57:117-123.

9. Rudnick, M., G. Morrison, B. Walker, and I. Singer. 1976. Renal failure, hemodialysis, and nafcillin kinetics. Clin. Pharmacol. Ther. 20:413-423.

10. Whitehouse, A. C., J. G. Morgan, J. Schumacher, and M. Hamburger. 1962. Blood levels and antistaphylococcal titers produced in human subjects by a penicillinase-resistant penicillin, compared with similar penicillins, p. 384-392. Antimicrob. Agents Chemother. 1961. 